\title{
Plasma steroid levels after intra-articular injection of prednisolone acetate in patients with rheumatoid arthritis
}

\author{
JANE S. REEBACK, ${ }^{1}$ J. CHAKRABORTY, ${ }^{2}$ JUDIE ENGLISH, ${ }^{2}$ \\ T. GIBSON, ${ }^{1}$ AND V. MARKS ${ }^{2}$ \\ From ${ }^{1}$ Guy's Arthritis Research Unit, Guy's Hospital Medical School, London, and the ${ }^{2}$ Division of Clinical \\ Biochemistry, Department of Biochemistry, University of Surrey, Guildford, Surrey
}

SUMMARY Eight patients with rheumatoid arthritis received an intra-articular injection of either $50 \mathrm{mg}$ or $100 \mathrm{mg}$ of prednisolone acetate into the knee joint. After the injection plasma levels of prednisolone were measured by radioimmunoassay and plasma cortisol levels were estimated fluorimetrically. Peak prednisolone levels were reached at between 2 and 4 hours after the intra-articular injection at both dosage levels, though the peak was higher with the larger dose. The $50 \mathrm{mg}$ dose did not have any effect on the plasma cortisol level at 24 or 48 hours, but there was some suppression of plasma cortisol levels for up to 48 hours after the $100 \mathrm{mg}$ dose.

The intra-articular use of steroids is now well established in the inflammatory arthropathies as an effective adjunct to other modes of treatment. The anti-inflammatory effect of the corticosteroid is believed to extend beyond the confines of the joint into which it has been injected, an effect which was noted early in the use of intra-articular steroid injection (Bywaters and Dixon, 1953). Systemic effects that have been observed include a fall in circulating eosinophils (Mason and Ward, 1953); suppression of plasma cortisol levels (Shuster and Williams, 1961); and suppression of the hypothalamic-pituitary axis (Koehler et al., 1974). These effects would all follow the absorption of corticosteroid from the synovial cavity, a phenomenon which has been shown directly with cortisol and indirectly with prednisolone derivatives (Bain et al., 1967).

Sensitive radioimmunoassay and competitive protein binding techniques are now available for the estimation of synthetic corticosteroids. One such procedure (English et al., 1974) was used in the present study in an attempt to confirm the systemic absorption of prednisolone acetate injected into an inflamed joint and to gauge the blood levels achieved.

Accepted for publication 8 February 1979.

Correspondence to Dr T. Gibson, Guy's Arthritis Research Unit, Guy's Hospital Medical School, London SE1.

\section{Patients and methods}

Eight patients, 4 males and 4 females, with rheumatoid arthritis participated in the study. They all had inflamed knee joints and were undergoing bed rest in hospital. One knee of each patient was aspirated as fully as possible and either $50 \mathrm{mg}$ or 100 $\mathrm{mg}$ of prednisolone acetate injected into the joint between 9 am and $11 \mathrm{am}$. None of the patients had received steroids either orally or by intra-articular injection for at least 2 months prior to the study. The first blood sample for steroid assays was withdrawn immediately before the injection, and subsequent samples were collected at intervals up to 48 hours. The patients remained on bed rest throughout this time. The plasma was separated and stored frozen until analysed.

\section{STEROID ANALYSES}

The measurement of prednisolone in plasma was carried out by the method previously described (English et al., 1974). The steroids were extracted from the plasma with acetone and separated by thin layer chromatography (silica gel HE 254 plates with $\mathrm{CH}_{2} \mathrm{Cl}_{2} / \mathrm{MeOH} / \mathrm{H}_{2} \mathrm{O}, 150 / 10 / 1 \mathrm{v} / \mathrm{v}$ as the solvent system). Prednisolone was then eluted and measured by the competitive binding system. Plasma fluorigenic 11-OH steroids, 'cortisol', were measured by a fluorimetric method (Mattingly, 1962). 


\section{Results}

Peak plasma prednisolone levels observed after a single $50 \mathrm{mg}$ injection are shown in Table 1 . These levels ranged from 119 to $417 \mathrm{nmol} / 1$ (43 to $150 \mathrm{ng} /$ $\mathrm{ml}$ ) and were reached between 2 and 4 hours after administration of the prednisolone. Small amounts of prednisolone ranging from 33 to $157 \mathrm{nmol} / 1$ (12 to $56 \mathrm{ng} / \mathrm{ml}$ ) were still detectable in the circulation of all patients after 24 hours. At 48 hours the amount of prednisolone remaining was too low to measure in 3 of the 6 patients and just detectable in the others. A $50 \mathrm{mg}$ dose of prednisolone had no demonstrable effect on plasma cortisol levels at 24 hours or 48 hours after administration (Table 2).

After $100 \mathrm{mg}$ of prednisolone 1 (no. 4) of the 3 patients studied had plasma prednisolone levels that were not markedly different from those observed in the same patient given a $50 \mathrm{mg}$ dose. In the other 2 patients, who had not been previously studied, peak plasma prednisolone levels were higher but were reached within the same time interval as the lower dose (Table 3). Appreciable amounts of the drug were still present in the blood at $24 \mathrm{~h}$ and $48 \mathrm{~h}$, and there was evidence of cortisol suppression in these cases even at $48 \mathrm{~h}$ (Table 2). No correlation was

Table 1 Plasma prednisolone concentrations in nmol/l after a single $50 \mathrm{mg}$ intra-articular injection of prednisolone acetate $(\mathrm{nmol} / \mathrm{l}=\mathrm{ng} / \mathrm{ml} \times 2 \cdot 78)$

\begin{tabular}{lccccccc}
\hline Patient no. & 30 min & $l h$ & $2 h$ & $4 h$ & $8 h$ & $24 h$ & $48 h$ \\
\hline 1 & - & + & 282 & 196 & 127 & 80 & + \\
2 & 80 & - & - & 119 & 99 & 33 & 28 \\
3 & - & 52 & 204 & 376 & 312 & 157 & 30 \\
4 & 138 & 190 & 403 & 237 & 190 & 63 & + \\
5 & + & 86 & 345 & 323 & 240 & 30 & 28 \\
6 & 80 & 177 & 362 & 417 & 395 & 47 & + \\
Mean & & 126 & 319 & 278 & 227 & 68 & 29 \\
S.E. & 34 & 35 & 46 & 46 & 19 & + \\
+=Not measurable; sensitivity of the assay & 15 nmol/l. $-=$ Not \\
sampled.
\end{tabular}

Table 2 Plasma cortisol levels (nmol/l) after a single intra-articular dose of prednisolone acetate (nmol/l= $n g / m l \times 2 \cdot 75)$

\begin{tabular}{|c|c|c|c|c|}
\hline \multirow[t]{2}{*}{ Patient no. } & \multirow{2}{*}{$\begin{array}{l}\text { Dose of } \\
\text { prednisolone }\end{array}$} & \multicolumn{3}{|c|}{ Morning cortisol level (nmol/l) } \\
\hline & & $\begin{array}{l}\text { Basal } \\
\text { value }\end{array}$ & $\begin{array}{l}24 h \text { after } \\
\text { dose }\end{array}$ & $\begin{array}{l}48 h \text { after } \\
\text { dose }\end{array}$ \\
\hline $\begin{array}{l}1 \\
2 \\
3 \\
4 \\
5 \\
6 \\
4 \\
7 \\
8\end{array}$ & $\begin{array}{l}50 \mathrm{mg} \\
50 \mathrm{mg} \\
50 \mathrm{mg} \\
50 \mathrm{mg} \\
50 \mathrm{mg} \\
50 \mathrm{mg} \\
100 \mathrm{mg} \\
100 \mathrm{mg} \\
100 \mathrm{mg}\end{array}$ & $\begin{array}{l}345 \\
284 \\
647 \\
734 \\
414 \\
386 \\
425 \\
450 \\
555\end{array}$ & $\begin{array}{l}309 \\
193 \\
326 \\
497 \\
425 \\
353 \\
166 \\
232 \\
127\end{array}$ & $\begin{array}{l}364 \\
229 \\
345 \\
834 \\
552 \\
375 \\
243 \\
293 \\
168\end{array}$ \\
\hline
\end{tabular}

Table 3 Plasma prednisolone concentrations (nmol/l) after a single $100 \mathrm{mg}$ intra-articular injection of prednisolone acetate $($ nmol $/ l=n g / m l \times 2 \cdot 78)$

\begin{tabular}{llllllrr}
\hline Patient no. & $30 \min$ & $\mathrm{lh}$ & $2 \boldsymbol{h}$ & $4 \boldsymbol{h}$ & $8 \boldsymbol{h}$ & $24 \boldsymbol{h}$ & $48 \boldsymbol{h}$ \\
\hline 4 & 138 & 199 & 342 & 144 & 113 & 50 & 22 \\
7 & 110 & 552 & 453 & 455 & 458 & 229 & 119 \\
8 & 593 & 654 & 777 & 814 & 649 & 290 & 210 \\
\hline
\end{tabular}

observed between individual patients' weight, disease activity (as reflected by the erythrocyte sedimentation rate), or volume of fluid aspirated from the joint and either the peak plasma prednisolone levels or the time at which the peak levels were reached.

\section{Discussion}

The data presented here show that prednisolone is absorbed from the synovial cavity but at a slower rate than after a comparable oral dose (Table 4) (figures derived from normal volunteers who took oral prednisolone: English et al., unpublished data). While in all cases plasma prednisolone levels reached a peak between 2 hours and 4 hours after the intraarticular injection, the peak concentration achieved varied with both the amount of steroid given and the individual patient. This is in agreement with the findings of Oka (1958), who measured plasma unconjugated 17-hydroxycorticosteroids by a modification of the Porter Silver reaction after the intraarticular injection of cortisol and cortisone. The difference between the levels reported in Oka's study and those presented here may be attributable in part to the use of a more specific and sensitive method of plasma steroid measurement in the present work as well as to differences in the nature of the steroid injected.

In contrast to the results presented here Esselinckz et al. (1976) have, in a preliminary communication, stated that plasma prednisolone concentrations did not reach their peak levels until $\mathbf{4 8}$ hours after intraarticular injection. These authors used 3 different derivatives of prednisolone-namely, the acetate, pivalate, and tributyl acetate-only one of which,

Table 4 Mean ( $\pm S D$ ) plasma prednisolone concentrations obtained in normal volunteers after a single oral dose of prednisolone $(\mathrm{nmol} / \mathrm{l}=\mathrm{ng} / \mathrm{ml} \times 2 \cdot 78)$

\begin{tabular}{lllc}
\hline Dose $(\mathrm{mg})$ & $\begin{array}{l}\text { Peak concentration } \\
(\text { nmol/l) }\end{array}$ & $\begin{array}{l}\text { Time after } \\
\text { dose }(h)\end{array}$ & $\begin{array}{l}\text { No. of } \\
\text { subjects }\end{array}$ \\
\hline 5 & $171 \pm 39$ & 2 & 5 \\
10 & $287 \pm 41$ & 1 & 10 \\
15 & $384 \pm 33$ & 1 & 6 \\
30 & $828 \pm 63$ & 1 & 6 \\
\hline
\end{tabular}




\section{Reeback, Chakraborty, English, Gibson, Marks}

prednisolone acetate, was chemically identical with the material used by ourselves. Differences in formulation may account for the discrepancy between their observations and our own, but further comparison must await publication of a fuller report of their findings.

In the present study the administered steroid, at both dosage levels, had largely disappeared from the circulation by $48 \mathrm{~h}$. After the smaller dose $(50 \mathrm{mg})$ there was insufficient prednisolone remaining in the circulation to produce consistent suppression of plasma cortisol levels at $24 \mathrm{~h}$ after the intra-articular injection. After the larger $(100 \mathrm{mg})$ dose, on the other hand, plasma cortisol levels were still suppressed after 48 hours. It is evident that measurement of plasma steroid levels following intra-articular injection of artificial steroid drugs and their effect on adrenocortical function warrant further attention.

The effect of the various recommended intraarticular dosage regimens on adrenal function cannot be fully predicted from the data presented here. It is likely that further investigation, especially of the newer synthetic corticosteroids, which are less water soluble than prednisolone acetate, and for which immunoassays now exist, will provide useful information on the difference between them, such as their therapeutic potency and duration of action.

We thank Dr R. Grahame for allowing us to investigate his patients; and the Arthritis and Rheumatism Council and Pharmax Ltd. for financial support.

\section{References}

Bain, L. S., Jacomb, R. G., and Wynn, V. (1967). Parenteral administration of $6 \alpha$-methyl prednisolone 21 acetate. Annals of Physical Medicine, 9, 49-54.

Bywaters, E. G. L., and Dixon, A. St. J. (1953). Effect of intra-articular injection of cortisone acetate and of hydrocortisone acetate in rheumatoid arthritis. Clinical Science, 12, 15-31.

English, J., Chakraborty, J., and Marks, V. (1974). A competitive protein binding method for plasma prednisolone assay. Annals of Clinical Biochemistry, 11, 11-14.

English, J., Chakaborty, J., and Marks, V. Unpublished data.

Esselinckz, W., Bacon, P. A., Collins, A. J., Crooke, D., Demoltaz, D., and Eing, E. F. J. (1976). Comparison of three intra-articular prednisolone analogues in rheumatoid synovitis. Abstracts of combined meeting. British Association for Rheumatology and Rehabilitation, the Heberden Society, the Royal Society of Medicine, and the Irish Society for Rheumatology and Rehabilitation at Dublin.

Koehler, B. E., Vrowitz, B., and Killinger, D. W. (1974). The systemic effects of intra-articular corticosteroids. Journal of Rheumatology, 1, 117-124.

Mason, H. L., and Ward, E. (1953). Systemic effects from hydrocortisone acetate administered intra-articularly to rheumatoid patients. Journal of Laboratory and Clinical Medicine, 42, 961-962.

Mattingly, D. (1962). A simple fluorimetric method for the estimation of free 11-hydroxycorticoids in human plasma. Journal of Clinical Pathology, 15, 374-379.

Oka, M. (1958). Absorption of acetates of hydrocortisone $\Delta^{1}$-hydrocortisone and cortisone from the joint cavity into the circulation. Journal of Endocrinology and Meta bolism, 18, 755-763.

Shuster, S., and Williams, J. A. (1961). Adrenal suppression due to intra-articular corticosteroid therapy. Lancet, 2, 171. 